been found to be of immense value in the biological control of mosquitoes. These researches are important and very interesting. The development of Aplocheilus is rapid, and metamorphosis takes place in about three weeks after hatching; from this stage onwards mosquito larvæ are eaten. The eggs of all the species of this genus are laid separately and are attached by threads to weeds. In Oryzias the female carries her eggs in clusters, in some species throwing them off so that they become entangled in weeds.
Thus there is a certain amount of parental care, and in O. melastigma they may or may not be carried until hatched. This species stays long in the larval state, and it may be one and a half months old before feeding on mosquito larvæ.

All these studies of life-histories are valuable, and it is hoped that more may be done on similar lines.

${ }^{1}$ Rec. Indian Mus., 41, Part 4 (1939).

${ }^{2}$ Rec. Indian Mus., 42, Part 1 (1940).

\title{
THE INORGANIC ELEMENTS IN NUTRITION
}

$\mathrm{E}^{\mathrm{x}}$ XTENSIVE investigations made within recent years and demonstrating the importance to human nutrition of minute quantities of various mineral elements were reviewed by Prof. E. V. McCollum, professor of biochemistry in the Johns Hopkins University School of Hygiene and Public Health, in a paper read at the University of Penn. sylvania Bicentennial Conference on September I7.

The early literature of nutritional research placed emphasis almost entirely on proteins, carbohydrates and fats, and gave little attention to the inorganic nutrients, in spite of the fact that Liebig, about 1830 , had shown the importance of minerals as fertilizers for the growth of plants. However, it must have been dimly appreciated that, since the bones contain so much calcium phosphate, an adequate supply of these elements must be provided for growing creatures. The appetite for common salt was accepted as evidence for the need of sodium and chlorine. Isolation of hæmoglobin by Hoppe-Seyler in 1862 stimulated investigations of the role of iron in the body, and during the last quarter of the nineteenth century physiologists studied some of the fundamental problems relating to the physiological action of salt solutions, including the development by Ringer of his famous solution. By the beginning of the twentieth century research in the mineral elements of nutrition had made much progress, and it is now known that at least thirteen inorganic elements are concerned with biochemical processes and must be provided in adequate amounts in the diet.

More than thirty years ago Dr. H. C. Sherman, of Columbia University, showed that calcium is one of the elements in which the human diet is frequently deficient. Milk and leafy vegetables are the only foods commonly eaten by man which are rich in calcium, and the rather poor utilization of the calcium of several green vegetables is due to their high content of oxalic acid, which interferes with calcium absorption. The calcium problem in human nutrition was intensified by the perfection of milling machinery so that all the mineral-rich parts of the grain could be removed from the part which is sold as flour, and to the rise during the last century and a half of the consumption of sugar, which now stands at an average of more than one hundred pounds per capita per annum. The large fraction of the total food supply taken in the form of refined cereals and sugar, the latter entirely free from mineral elements, puts upon the remaining portion of the diet the burden of supplying almost the entire inorganic needs of the body.

The effects of calcium deficiency range from a decreased rate, or cessation of growth, to premature death. Many of the effects are due to the shortage of this element in the blood, which normally contains only 1 per cent or less, of all the calcium in the body, 99 per cent being in the bones and teeth.

Prof. McCollum referred briefly to the researches conducted around 1922 which showed that lack of vitamin $\mathrm{D}$ was a principal cause of rickets, a disease in which there is poor development of bones and teeth. Previous to 1922, the cause of rickets was unknown, although the disease had afflicted millions of infants and children in temperate regions throughout the world during many hundreds of years. Simply supplying calcium and phosphorus, the main ingredients of bone, was not sufficient. These minerals could not be built into bone, it was then found, without the assistance of vitamin D. It was Prof. McCollum and his associates who demonstrated this fundamental fact by noting that the sudden introduction of cod liver oil into the diet of a rat with rickets was followed by deposition of lime salts in the bone. The freshly deposited lime showed in the $\mathrm{X}$-ray as a distinct line across the head of the bone, and became a test of the curative effects in treating rickets. It was later shown by a number of research workers that sunlight on the body or artificial irradiation of foods caused the formation of vitamin $D$ in the body or foods and prevented or corrected rickets in children.

Next to the nutritional problems traceable to deficiencies of calcium and phosphorus and vitamin $D$ (and these are now in great measure being prevented), anæmia due to deficiency of iron is perhaps the most widespread inorganic nutritional problem. Apparently about 50 per cent of the iron in cereal grains and certain other common goods is in the so-called 'hæmatin' form, in which it is not available for assimilation by man or animals. It has been noted that the utilization of iron by the system is impaired when the supply of ascorbic acid (vitamin C) in the diet is inadequate, and there are reports that anæmic persons on a low iron diet show a marked response in the number of red blood cells and the hæmoglobin percentage when ascorbic acid is given to them. Also iron tonics in certain cases have led to no improvement in the blood until fresh fruits or raw vegetables which are goad sources of vitamin $\mathrm{C}^{-}$are included in the diet. Prof. MeCollum remarked that preventable or curable anæmia is so widespread and so common that these newer observations on the manner of assimilating iron are of great practical significance.

It has been shown also that copper is important in connexion with the utilization of iron, and that copper deficiency is fairly widespread among infants. 
One of the most interesting mineral elements, in its behaviour in the animal body, is manganese. Rats given a diet deficient in manganese were unable to suckle their young, and they showed no normal maternal instincts. Many of the neglected young rats died within a few hours. Deficiency of manganese in chickens produces a condition known as 'slipped tendon', or perosis, in which the angle joint is displaced and the birds crippled so badly they usually die. Hens deficient in manganese lay eggs of very low hatchability, many of the chicks dying in the shell a few days before the time for hatehing. These embryos are often deformed, having short, thickened leg and wing bones and globular heads. When manganese is injected into hens deficient in the mineral the eggs hatch normally and produce chicks with normal bones. At present there is no evidence concerning the occurrence of manganese deficiency in human beings.

Reference was also made by Prof. McCollum to the demonstration of cobalt deficiency as the cause of a blood disease in sheep and cattle known variously throughout the world as 'Denmark disease', 'coast disease', the 'pines', 'bush sickness', and 'salt sick'. The animals suffering from the disease were found to have been grazing on pastures the soil of which was deficient in cobalt. The investigations which proved the point constitute one of the classics of nutritional research. This disease, it will be recalled, has been the topic of articles and correspondence in NATURE during recent years.

\section{AFFINITIES IN THE PUEBLO CULTURE OF ARIZONA*}

$\mathrm{D}^{\mathrm{n}}$ . FRANK H. H. ROBERTS, JUN., continues his report on his archæological excavations of the Whitewater Anasazi or Basket-Maker-Pueblo remains in Eastern Arizona (see NaTuRE, 144, 556; 1939) by an account of the pottery, and objects of bone, stone and shell which were found, as well as of the burials which were examined. From the burials skeletal remains of 150 individuals were discovered, but of these 15 only were sufficiently well preserved to permit of recovery, examination and report.

The objects recovered by the investigation permit of a very partial view only of the material culture of the inhabitants. Virtually the whole of the products of their industry made of perishable material is missing. A few potsherds bear the impress of basketry, while a few charred pieces of cord were found. The basketry was of the characteristic coiled form. There is no evidence of clothing, textiles or wooden imple. ments, though these must have played a large part in their lives.

The specimens collected were found in the remains of houses, in the various refuse mounds, as offerings accompanying burials, in a few instances on the old occupation surface near dwellings and outside firepits. No articles appear to have been made specially for funerary purposes.

Most of the artefacts represent one stage, the Developmental Pueblo, though there are a few from the earlier stage, the Modified Basket:Maker, and the later, the Great Pueblo. Dated timbers from the various structures indicate datings ranging from the early part of the ninth century to the early years of the eleventh century A.D. Pottery sequences have been checked and confirmed by stratigraphic evidence.

True pottery first appears in the Anasazi province in the Modified Basket-Maker stage. Vessels were occasionally made of unfired clay tempered with shredded cedar bark or grass, the prototype of the later makes that came to play so prominent a part in the life and industry of the people. In some

* Smithsonian Institution, Bureau of American Ethnology, Bull. 126. Archæological Remains in the Whitewater District, Eastern Arizona. Pt. 2. Artifacts and Burials. By Frank H. H. Roberts, Jr. With an appendix: Skeletal Remains from the Whitewater District, Eastern Arizona. By T. D. Stewart. Pp. xi $+170+57$ plates. (Washington, D.C.: G.P.O.) 50 cents. instances the bottoms were moulded in baskets, the walls or rims being formed of fillets of clay looped around the upper edges. Others were fashioned entirely by hand without basal support by a coiling process. The principal shapes were shallow trays and deep bowls. The unfired clay objects may be attributed to influences from regions to the south but the methods used seem to have been mainly indigenous, since the Basket-Makers were already adepts in the use of clay for architectural purposes, as for example in the jug-like necks of the tops of their granaries and the mud steps placed on granary walls. When firing of clay developed, the cedar bark binder was replaced by sand, which in turn was gradually replaced by powdered rock, and this in the Developmental Pueblo period by ground potsherds.

The Modified Basket-Maker phase had developed a variety of shapes in its pottery, while protruding particles in the paste gave it a characteristic irregularly stippled appearance. Decoration for the most part was confined to the interior of bowls and was produced by the use of carbon which was prevalent in north-eastern Arizona, and an iron, which was widely distributed over the remainder of the area. The designs are generally ribbon-like panels embellished with dots, zig-zags, and stepped line elements. The opening of the Developmental Pueblo period witnessed changes. New features were introduced and there was a marked expansion in the industry. Surfaces were carefully smoothed and the application of a step was introduced. A great diversity of form is shown with colour; plain grey, black on white, black on red, and brown with a brownish exterior and a slightly burnished interior. All types of vessel are decorated. There are two main groups of the light-coloured vessels ornamented with black, of which one occurs throughout the eastern part of Arizona centring about the Chaco Canyon area, and the other predominating in the west.

On the Whitewater site, stratigraphic tests show a definite progression in pottery forms and a certain sequence in the appearance of types. This is augmented by the association between ceramic styles and house remains and an indication of a certain 